\title{
ACORDO DE NÃO PERSECUÇÃO PENAL NOS CRIMES DE "COLARINHO BRANCO”: REFLEXOS DIRETOS NAS SOCIEDADES EMPRESARIAIS
}

\author{
Robson Martins ${ }^{1}$ \\ Warley Freitas de Lima² \\ Naara Maria de Sousa ${ }^{3}$
}

\section{RESUMO}

O Acordo de Não Persecução Penal, instituto da justiça consensual penal, com aplicação em todas as searas do direito penal, gerará reflexos significativos no âmbito empresarial, com mudanças na gestão das empresas públicas e privadas. O investigado que vislumbrar possibilidade de cond enação poderá optar pelo cenário que apresente menos riscos a si próprio, sem analisar o impacto deletério na empresa da qual faz parte, que poderá responder civil e administrativamente. Com tal risco imediato, as empresas, diante dos maiores riscos de serem responsabilizadas por possíveis condenações de seus colaboradores, optarão por adotar práticas de compliance, não compactuando com posturas antiéticas, corruptas e criminosas, criando um desestímulo a tais condutas ilegais, seja por parte das lideranças ou de seus colaboradores, diminuindo a prática, inclusive, de corrupção endêmica na administração pública.

Palavras-chave: Acordo de Não Persecução Penal; Empresas; Combate aos Crimes; Colarinho Branco; Compliance.

Recebido em: 12 de dezembro. 2020

Aceito em: 23 de março. 2021

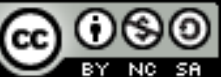

\footnotetext{
${ }^{1}$ Doutorando em Direito na Instituição Toledo de Ensino - ITE. Mestre em Direito Processual e Cidadania pela Universidade Paranaense. Especialista em Direito Notarial e Registral, bem como Direito Civil pela Universidade Anhanguera - Uniderp. Graduado pela Universidade Paranaense. Procurador da República lotado no $8^{\circ}$ Ofício Criminal da PRPR. Professor dos cursos de Pós Graduação do Centro Universitário Internacional - Uninter e da Instituição Toledo de Ensino - ITE. Email: warley1966@uol.com.br
}

2 Doutorando em Direito na Instituição Toledo de Ensino (ITE- BAURU). Mestre em Direito pelo Centro Universitário Salesiano de São Paulo (UNISAL-LORENA). Especialista em Direito do Estado pela Universidade Gama Filho (UGF-RJ). Graduado pela Universidade de Taubaté (UNITAU). Advogado. Professor da Universidade Vale do Paraíba (UNIVAP). Membro do Instituto Brasileiro de Ciências Criminais (IBCCRIM). Membro do Instituto de Defesa do Direito de Defesa - IDDD.

${ }^{3}$ Graduanda em Direito pela Universidade do Vale do Paraíba - Univap. Estagiária na Defensoria Pública Estadual em São José dos Campos - SP. 


\title{
AGREEMENT OF NON-CRIMINAL PUNISHMENT IN THE CRIMES OF "WHITE COLLAR": DIRECT REPERCUSSIONS IN BUSINESS SOCIETIES
}

\begin{abstract}
The Agreement of Non-Criminal Prosecution, institute of consensual criminal justice, with application in all areas of criminal law, will generate significant repercussions in the business field, with changes in the management of public and private companies. The investigated person who envisions the possibility of conviction, may opt for the scenario that presents less risks to himself, without analyzing the deleterious impact on the company of which he is part, which may respond civilly and administratively. With this immediate risk, companies, faced with the greatest risks of being held responsible for possible convictions of their employees, will choose to adopt compliance practices, not compacting with unethical, corrupt and criminal postures, creating a disincentive to such illegal conduct, either by the leaders or their employees, reducing the practice, including endemic corruption in the public administration.
\end{abstract}

Keywords: Agreement of non-criminal prosecution. Effects. Companies. Compliance.

\section{INTRODUÇÃO}

O Acordo de Não Persecução Penal ganha espaço negocial, sendo uma forma de justiça penal consensual, incorporado ao Código de Processo Penal por meio do chamado "pacote anticrime", por meio da Lei $\mathrm{n}^{\circ} 13.964 / 19$, com o escopo de gerar maior celeridade às investigações e às atividades jurisdicionais e do Ministério Público brasileiro (BRASIL, 2019).

Deveras, trata-se de uma inovação no sistema processual penal brasileiro, pois é: “[...] mais um instrumento de ampliação do espaço negocial, pela via do acordo entre MP e defesa" (LOPES JUNIOR, 2020, p. 220). A Constituição Federal, em seu artigo 98, inciso I, já previa a criação, pela União e Estados, dos:

[...] juiza dos especiais, providos por juízes togados, ou toga dos e leigos, competentes para a conciliação, o julga mento e a execução de causas cíveis de menor complexidade e infrações penais de menor potencial ofensivo, mediante os procedimentos oral e sumaríssimo, permitidos, nas hipóteses previstas em lei, a transação e o julga mento de recursos por turmas de juízes de primeiro grau (BRASIL, 1988.s.p.).

Portanto, atendendo ao apelo do constituinte, a justiça consensual penal foi introduzida no país desde a Lei 9.099/95. Assim, há mais de25 anos há a previsão de suspensão condicional do processo, bem como de transações penais (BRASIL, 1995).

Posteriormente houve a colaboração premiada, especialmente introduzida através do artigo 3-A da Lei 12.850/2013, que determina: “O acordo de colaboração premiada é negócio 
jurídico processual e meio de obtenção de prova, que pressupõe utilidade e interesse públicos" (BRASIL, 2013, s.p.).

Acerca da colaboração premiada, verifica-se que esta se diferencia do Acordo de Não Persecução Penal porque, essencialmente, possui um fator ativo do autor do delito, já que este produz provas contra os demais integrantes da organização criminosa, ou seja, "consiste no meio especial de obtenção de prova - técnica especial de investigação" (MASSON, 2020, p. 166)

Outrossim, o prêmio ao colaborar é diverso do Acordo de Não Persecução Penal, pois poderá inclusive obter perdão judicial, diferentemente do Acordo de Não Persecução Penal, em que sempre haverá imposição de algumas sanções. Mas há pontos de contato entre os dois institutos, pois o autor do delito:

“[...] coopera com os órgãos de persecução penal confessando seus a tos e fornecendo informa ções objetiv a mente efica zes quanto à identidade dos demais sujeitos do crime, à materialidade das infrações penais por eles cometidas, a estrutura da organização criminosa, a recuperação de ativos, a prevenção de delitos ou a localização de pessoas"(MASSON, 2020,p. 167).

De outro giro, em 07 de agosto de 2017 a Resolução no 181 do Conselho Nacional do Ministério Público (CNMP) introduziu, no ordenamento jurídico, o Acordo de Não Persecução Penal, contudo, houve sérias manifestações contrárias acerca de tal instituto, criado pelo CNMP, eis que se trata de matéria processual penal, e apenas o Congresso Nacional teria legitimidade para fazê-lo.

Deveras, apenas lei pode introduzir normas penais ou de processo penal, em face do princípio da legalidade, que é "o mais importante instrumento constitucional de proteção individual no moderno Estado Democrático de Direito" (SANTOS, 2018, p. 22).

Contudo, após aprovação no legislativo e sancionado pelo Presidente da República, o Acordo de Não Persecução Penal é dotado de um caráter pré-processual, através de negociação entre o acusado e o órgão de acusação - no caso, o Ministério Público, Federal, Eleitoral, Militar ou Estadual.

Posteriormente à celebração do acordo entre o MP e a defesa, há a homologação por parte dojuízo da Vara Criminal competente, possibilitando a resolução de conflitos criminais de forma mais célere e menos morosa, uma vez que se utiliza de meios de reparação distintos do encarceramento e evita o transcorrer da ação penal. 
Torna-se claro, portanto: "Se fizermos um estudo dos tipos penais previstos no sistema brasileiro e o impacto desses instrumentos negociais, não seria surpresa alguma se o índice superasse a casa dos 70\% dos tipos penais passíveis de negociação, de acordo" (LOPES JUNIOR, 2020, p. 220).

Deveras, desde que preenchidos os requisitos, a possibilidade de negociação atinge também os chamados "crimes do colarinho branco", que são graves crimes corporativos, cometidos com grande frequência em ambientes empresariais por motivação financeira, porém sem violência.

Entre os chamados "crimes de colarinho branco" mais cometidos no contexto empresarial, podem-se mencionar, de forma exemplificativa: corrupção ativa, fraude, lavagem de dinheiro, sonegação fiscal, crimes contra o sistema financeiro, crimes contra a ordem econômica, falsificação, extorsão, suborno e apropriação indébita, entre outros.

Neste cenário, considerando essa nova estratégia de persecução penal, adentrando às peculiaridades do caso concreto, as empresas precisarão de novo viés de desafio para trilhar o espaço empresarial. É que quando um de seus colaboradores estiver na condição de investigado pelo cometimento de um crime empresarial, o Acordo de Não Persecução Penal exigirá, pelo Parquet, como condição para sua efetivação, a confissão formal e circunstanciada por parte do colaborador investigado.

Tal conduta trará ao infrator, pessoa física, punição mais branda, contudo, não isentará de forma alguma a responsabilização objetiva da empresa e as consectárias punições civis e administrativas.

\section{OBJETIVOS}

O objetivo do presente artigo é analisar o novel instituto do Acordo de Não Persecução Penal (ANPP), com seus possíveis reflexos quanto aos denominados "crimes de colarinho branco" cometidos no ambiente empresarial do país, apontando os novos desafios empresariais e, ainda, possibilidades de soluções práticas, com a efetivação de compliance pelas diretorias, além de reproche às atividades ilícitas internamente.

As empresas, com tal vertente de persecução penal de seus colaboradores ou dirigentes, terão uma nova formatação para trabalhar de maneira honesta e legal, sem práticas nefastas que possam levá-las a rigorosas punições civis e administrativas, inclusive com a própria extinção das sociedades, dado o rigor da lei.

Rev. CEJUR/TJSC |Florianópolis (SC)| v.9.n.1|e360| p.01-15 | Janeiro-Dezembro | 2021. 


\section{METODOLOGIA}

A pesquisa ora elaborad a visa a analisar os efeitos dos Acordos de Não Persecução Penal no seio empresarial, e quais boas práticas podem ser analisadas pelas empresas, no escopo de minimizar os reflexos de situações desonestas de dirigentes e colaboradores.

Nesse ínterim, a pesquisa será de aspecto qualitativo, uma vez que "a partir do momento em que a pesquisa se centra em um problema específico, e em virtude desse problema específico o pesquisador escolhe o procedimento mais apto, segundo ele, para chegar à compreensão visada" (LAVILLE; DOINNE, 1999, p. 43).

Dentre os modos ou estratégias de análise e interpretação compreendidas pela abordagem qualitativa, foi utilizado o emparelhamento (pattern-matching), que "consiste em emparelhar ou, mais precisamente, em associar os dados recolhidos a um modelo teórico com a finalidade de compará-los" (LAVILLE; DOINNE, 1999, p. 129).

No que se relaciona ao método de procedimento foi utilizado o tipológico que, por sua vez, se volta a comparar fenômenos sociais complexos, criando "tipos ou modelos ideais, construídos a partir da análise de aspectos essenciais do fenômeno" que, todavia, não existem na realidade (MARCONI; LAKATOS, 2017, p. 109).

No uso desse método, "o papel do cientista consiste em ampliar certas qualidades e fazer ressaltar certos aspectos do fenômeno que se pretende analisar" (idem, 2017, p. 109) que, na pesquisa ora proposta, são os reflexos do acordão de não persecução penal nas gestões das empresas, especialmente a adoção de técnicas de compliance.

Quanto às técnicas de pesquisa, utilizadas foram a bibliográfica e a documental - que, realizada em torno de uma questão, determina a revisão de todos os trabalhos disponíveis, selecionando tudo quanto possa servir à pesquisa, para "encontrar os saberes e pesquisas relacionadas à questão" (LAVILLE; DOINNE, 1999, p. 113).

A pesquisa busca trabalhar questões práticas atinentes aos Acordos de Não Persecução Penal, precipuamente nos "crimes de colarinho branco", buscando a preservação das empresas e a própria paz social, com uma economia fundada em boas práticas de compliance. 


\section{PROBLEMA}

Inicialmente, imperioso ressaltar que o Direito Penal é "aquela parte do ordenamento jurídico que fixa as características da ação criminosa, vinculando-lhe penas ou medidas de segurança” (WELZEL, 1970, p. 11).

Neste prisma, o direito penal, embora tenha consigo o princípio da ultima ratio, no sentido de que apenas quando as outras áreas do Direito não funcionarem ele deveria atuar, certamente é um dos maiores problemas da criminologia.

Assim, no primeiro momento, há um desiderato do direito penal de combater o crime, contudo: "não se pode dizer que essa missão seja exclusiva do direito penal" (TOLEDO, 1994, p. 6). Por certo, o combate ao crime é uma responsabilidade do Estado, mas dever também de todo a sociedade, incluindo as empresas. "Pelo menos na luta preventiva contra o crime estão (ou deveriam estar) envolvidos, cada um a seu modo, importantes setores da vida comunitária: família, escola, órgãos assistenciais, sobretudo os de proteção ao menor etc.” (idem, 1994, p. $6)$.

Portanto, na aplicação do Acordo de Não Persecução Penal, o autor do delito, dirigente, colaborador ou/e empregado da empresa, visando à acessibilidade a uma sanção penal menor, menos impactante para si próprio, poderá produzir sozinho um meio de prova que poderá afetar diretamente a empresa, numa concatenação de atos.

Isto resultará na necessidade de produção de prova em sentido contrário por parte da empresa que manifeste intenção de afastar tal responsabilidade. Essa responsabilidade objetiva daempresa ad vém da Lei 12.846 de 2014, conhecida como Lei Anticorrupção Empresarial, que tornou possível a responsabilização empresarial pelos atos de corrupção de seus funcionários (BRASIL, 2014).

Tal lei possibilita que as empresas sejam responsabilizadas e punidas civil e administrativamente pelos danos causados, independentemente de comprovação de culpa ou dolo das pessoas específicas que agiram por meio da instituição, bastando tão somente comprovar-se a existência do fato, o resultado e o nexo de causalidade entre a conduta e o dano ocorrid o com a atividade (BRASIL, 2014).

Inexiste no país a responsabilidade penal objetiva, por parte das empresas. Contudo, estas sofrerão os reflexos da confissão por parte do agente para fins da aplicação do Acordo de Não Persecução Penal, bem como as penalidades impostas. 
A referida Lei de Anticorrupção Empresarial aplica-se às sociedades empresárias ou simples, fundações, associações de entidades ou pessoas e socied ades estrangeiras com sede ou filial no território brasileiro. Administrativamente, a aplicação de tal lei pode ser por parte dos Estados, União, Distrito Federal e municípios, e as sanções poderão incidir multa de 0,1\% a $20 \%$ do faturamento bruto da instituição, bem como publicação extraordinária da decisão condenatória.

Na esfera judicial, os entes federativos e o Ministério Público podem promover ação contra empresas infratoras, buscando a aplicação de sanções consubstanciadas no perdimento dos bens, direitos ou valores que tenham sido obtidos de forma direta ou indireta pelo ato de corrupção.

Poderá existir também a suspensão ou interdição parcial de suas atividades; dissolução compulsória da Pessoa Jurídica e proibição de receber incentivos, subsídios, doações, subvenções ou empréstimos de órgãos ou entidades públicas, ou entidades financeiras públicas ou controladas pelo poder público, durante um prazo entre um a cinco anos (BRASIL, 2014).

Destarte, quando o réu na ação penal é dirigente, colaborador e/ou empregado de determinada empresa e vislumbra, diante do cometimento de um dos chamados crimes de “colarinho branco", no contexto do seio empresarial, a possibilidade da aplicação do Acordo de Não Persecução Penal e efetiva a aplicação do instituto negocial pode-se, de forma direta, acabar refletindo negativamente na responsabilidade objetiva da empresa, que diretamente sofrerá aplicação de sanções civis, tributárias e administrativas, ainda que não criminais.

\section{FUNDAMENTAÇÃO TEÓRICA}

No decorrer deste trabalho, imprescindível a conceituação mais específica a respeito do Acordo de Não Persecução Penal. Acerca do referido instituto:

[...] trata-se, em verdade, de legítimo instrumento de política criminal, por meio do qual o Ministério Público exerce seu papel constitucional de agente catalisador e transformador da realidade criminal brasileira e por isso desenvolve estratégia de repressão, prevenção e tra tamento das consequências da criminalidade, sejam vítimas identificadas, sejam danos sociais (SOUZA et al. 2020, p. 147).

No mesmo sentido, aponta-se:

[...] um poderoso instrumento de negociação processual penalque requer uma postura diferenciada por parte dos atores judiciários, antes forjados no confronto, que agora precisam abrir-se para uma lógica negocial, estra tégica, que demanda uma análise do 
que se pode oferecer e do preço a ser pago (prêmio), do timing da negociação, da arte negocial (LOPES JR, 2020, p. 315).

Outrossim, cuida-se: “[...] de negócio jurídico de natureza extrajudicial, necessariamente homologado pelo juízo competente - pelo menos em regra, pelo juiz das garantias" (LIMA, 2020, p. 274). Portanto, o artigo 28-A, inserido no Código de Processo Penal por meio do Pacote Anticrime, apresenta requisitos para uma possível proposta de aplicação do instituto de Acordo de Não Persecução Penal.

Dentre os requisitos, a lei apresenta: 1) confissão por parte do investigado; 2) infração penal sem violência ou grave ameaça; e 3) pena mínima inferior a quatro anos (BRASIL, 2020).

Existem condições específicas a serem negociadas de forma alternativa ou cumulativa, que são: reparação do dano ou restituição da res furtiva, salvo impossibilidade de fazê-lo; renúncia dos instrumentos, produtos ou proveitos do crime que forem indicados pelo Ministério Público; prestação de serviço à comunidade por período correspondente à fração mínima cominada ao delito diminuída de um a dois terços; e pagamento de prestação pecuniária à entidade de interesse público ou social, podendo-se considerar a imposição de outras cond ições proporcionais ao crime imputado.

Torna-se hialino que o Acordo de Não Persecução Penal não isenta o investigado de sanções, mas indiscutivelmente é uma opção vantajosa diante de um cenário que não lhe seja favorável, seja pelo fato de o investigado ser, de fato, o autor ou coautor do delito, ou pelo fato de, mesmo não sendo, as provas se tornarem desfavoráveis a ele.

Deveras, é possível vislumbrar que grande parte dos processos criminais nos quais ocorre investigação pelo cometimento de algum dos crimes classificados como "crime de colarinho branco" serão resolvidos por meio de negociação junto à defesa e ao MP, nos termos da lei. Neste viés, com esses esclarecimentos, pode-se aprofund ar o estudo a respeito do grande impacto que tal medida negocial causará nas investigações criminais no âmbito empresarial.

Aqui, torna-se importante mencionar brevemente a origem da ideia de "crimes do colarinho branco", que teve como marco inicial estudos do sociólogo Edwin Hardin Sutherland (2015). Em um artigo publicado em 1940, intitulado "White collar criminality”, o autor abordou o tema sob um aspecto criminológico.

Em sua visão, sucintamente, os "crimes do colarinho branco" seriam aqueles aprendidos no exercício profissional de indivíduos considerados pertencentes a uma classe de elevado status social. Essa modalidade criminosa, justamente por ser cometida grande parte das vezes 
por agentes com grande poder aquisitivo, em ambientes empresariais, dificulta as investigações e consequentes punições, em face da própria conjuntura fática da prática delituosa.

Portanto, as possíveis causas para impunidade diante do cometimento de crimes desta espécie são:

[...] a.forte poder econômico e social dos autores; b. cumplicida de das a utorida des; c. privacidade que caracteriza a vida e atividade dos autores; d. complexidade das leis especiais que, às vezes procuram regular estes fatos, as quais pode ser manipuladas por hábeis advogados e contabilistas; e. prática atra vés de empresas, tornando difusa a responsabilidade penal e dificultando a aplicação das diferentes leis nacionais, quando se trata de multinacionais; f. tendência a acreditar que as empresas maiores e mais importante são mais honestas do que as pequenas, reforçada por técnicas publicitárias para conservar a aceitação do público e manter sua boa imagem (CASTRO, 1983, p. 55-56).

No site do Departamento Federal de Investigação dos Estados Unidos (FBI) há uma pormenorização da prática de delitos de colarinho branco, caracterizando-o como:

[...] sinônimo de toda a gama de fraudes cometidas por profissionais de negócios e governo. Esses crimes são caracterizados por engano, dissimulação ou violação de confiança e não dependem da aplicação ou ameaça de força física ou violência. A motivação por trás desses crimes é fina nceira - para obter ou evitar a perda de dinheiro, propriedade ou serviços ou para garantir uma vantagem pessoal ou comercial (EUA, 2020 , s.p.).

Nessa toada, no âmbito empresarial, o combate aos referidos delitos ganha uma complexidade superior, considerando a grande possibilidade dos envolvidos possuírem alto poder econômico, influência e autoridade decorrente de cargos elevados dentro de certa empresa. Ademais, importante salientar que acompanhados dos delitos de "colarinho branco" há geralmente os delitos vinculados à corrupção na administração pública:

[...] Essa confluência de fatores implicaria que nesses ambientes sociais teria sido gerado uma espécie de círculo vicioso que a limenta a desconfiança social, incentiva o funcionamento parcial das instituições governamentais e, em última instância, produz uma corrupção enraiza da e onipresente que é muito difícil de combater. Dessa forma, naqueles sistemas políticos em que as políticas governamentais são ineficientes, parcia is (buscam o benefício de determina dos grupos sociais) e corruptas, o desenvolvimento de um senso de solidariedade social é impossível e a confiança particularizada em diferentes grupos sociais é estimulada acima da confiança genera lizada em toda a sociedade (SANCHES, 2016,p. 2).

É que a falta de confiança na administração pública, acaba se traduzindo em outras ilegalidades, em um círculo vicioso de crimes e desmandos:

[...] Quando isso acontece, quando a confiança predominante é aquela colocada na própria família, clã, etnia ou partido político, a política nessa sociedade se torna "um 
jogo de soma zero entre grupos conflitantes" (Rothstein e Uslaner, 2005: 45 -46). Não aparecem nessas sociedades regras informais que promovam a produção de bens públicos, como o respeito aos espaços públicos ou as regras básicas de convivência social. Em vez disso, criaram uma prática social preda tória do "salve-se quem puder" que impossibilita o poder público de ter os recursos e incentivos necessários para a realização de políticas que promovam a solidariedade social necessária para se sentirem envolvidas na mesma comunidade. Pelo contrário, as políticas governamentais serão incentivadas por uma lógica particularista e parcial que abundará na espiral do círculo vicioso" (SANCHES, 2016, p. 2).

Não é por acaso, portanto, que as sanções no âmbito da administração pública, para o combate à corrupção, devem ser cada vez mais apuradas:

\begin{abstract}
No contexto atual de constante descoberta de casos envolvendo corrupção em todos os níveis da Administração Pública brasileira, esse tipo de ilícito parece ter chegado a patamares antes não ima gina dos. A corrupção é comparada a uma endemia e tem se desenhado em uma estrutura transnacional e altamente organizada, causando gra ves danos à sociedade e ao Estado, pois prejudica o desenvolvimento econômico e fragiliza a democracia. Sendo assim, as instituições envolvidas no combate à corrupção têm buscado novos instrumentos e técnicas ma is consentâneas com a evolução da própria criminalidade. As experiências positivas em diversos países a ponta m que o teste de integrida de, ca so a dequadamente conduzido, é uma ferra menta altamente eficaz no enfrentamento à corrupção na Administração Pública (OLIVEIRA, 2017,p. 619-639)
\end{abstract}

Portanto, quando cometido o delito por um subordinado ou empregado, no âmbito empresarial, a persecução penal também é extremamente complexa, já que havendo eventual condenação, com a confissão, poder-se-á imputar à empresa responsabilidade civil objetiva, o que gerará reflexos deletérios, ainda que apenas civil e administrativamente. No que tange à responsabilidade objetiva das empresas:

\footnotetext{
Responsabilidade objetiva significa punir diretamente as empresas sem necessidade de comprovação de culpa ou dolo das pessoas físicas envolvidas. Basta que se comprove a ocorrência de pelo menos um dos atos lesivos previstos no art. $5^{\circ}$ da Lei $\mathrm{n}^{\mathrm{o}} 12.846 / 2013$ e que tais atos foram cometidos em interesse ou benefício da pessoa jurídica. Responsabilidade objetiva não significa, de forma alguma, deixar impunes as pessoas físicas envolvidas. O artigo $3^{\circ}$ da Lei $n^{\circ} 12.846 / 2013$ é claro no sentido de que a responsabilização da pessoa jurídica não exclui a responsabilidade individual de seus dirigentes, administra dores ou de qua lquer pessoa natural, autora, coautora ou partícipe do ato ilícito. O ponto central da responsabilidade objetiva é que a responsabilização da pessoa jurídica não é condicionada ao prosseguimento ou decisão final acerca da responsabilidade das pessoas físicas (CAPANELA, 2014, p. 17).
}

$\mathrm{Na}$ análise do autor, há menção de que na grande maioria dos casos de delitos de “colarinho branco" a responsabilização da pessoa jurídica só existe quando da identificação da pessoa física, "mas ocorre que o avanço na responsabilização de pessoas físicas depende da 
comprovação de culpa e dolo, aspectos cuja discussão pode se arrastar por muito tempo, ainda mais se considerarmos a morosidade do nosso processo penal" (CAPANELA, 2014, p.17).

Neste viés, verifica-se que a maioria dos delitos cometidos no contexto laboral por dirigentes ou funcionários de grandes, médias ou pequenas corporações empresariais, faz parte do mencionado rol de "crimes de colarinho branco" e comportam a aplicação do Acordo de Não Persecução Penal, conforme aludido anteriormente.

Importante, então, que as empresas adotem posturas de compliance, ou seja, possuindo órgãos internos de aferição de integridade, de legalidade, com controles eficazes internos e externos, políticas e diretrizes claras estabelecidas para os dirigentes e colaboradores. Tal novel postura deve assegurar, a todo custo, o cumprimento das regras estatais e empresariais préestabelecidas, com definição de órgão de regulamentação e padrão direcionad o à estruturação de seu viés empresarial.

Embora tenhamos um longo caminho pela frente, para enfrentarmos a macrocriminalidade e principalmente os crimes de 'colarinho branco', verifica-se que a nova legislação tornará a justiça penal inovadora, mais justa e eficiente:

\begin{abstract}
Os dados apresentados neste livro sobre a persistente realidade carcerária brasileira, somados à surpreendente quantidade de crimes do colarinho branco noticiadas diariamente na imprensa, podem passar a enganosa impressão que nada mudou no Brasil. Mas essa é apena s uma fotografia do momento, que não reflete a evolução que vivenciamos. As duas frentes da seletividade do nosso sistema têm sido atacadas: os crimes econômicos, a passos lentos, estão sendo removidos da sombra tranquila da impunidade: e os Poderes Legislativo e Judiciário, assim como a própria sociedade, vêm despertando para os males da cultura do aprisionamento, com a criação de medidas despenalizadoras, a realização de mutirões carcerários, a implantação de audiências de custódia e o afastamento de leis desproporcionalmente rigorosas ou violadoras de direitos fundamentais (CRUZ, 2020, p. 365-366).
\end{abstract}

Torna-se inevitável, portanto, que a organização empresarial terá de lidar com um aumento nos casos em que será apontada sua responsabilidade objetiva, diante de confissão de colaboradores investigados.

\title{
6. CONCLUSÕES
}

Com este artigo abordou-se que, existindo o cometimento de "crimes de colarinho branco" no contexto empresarial, a aplicação do Acordo de Não Persecução Penal gerará reflexos significativos nas relações empresariais.

Conquanto seja um ato negocial entre o Ministério Público e a pessoa acusada ou investigada por um delito, tendo por consequência a diminuição do fluxo infindável de 
processos penais nas Varas Criminais, haverá reflexo direto nas atividades empresariais. É que como consequência direta dos acordos de não persecução envolvendo tais dirigentes ou colaboradores, as empresas necessitarão de mudanças drásticas na sua própria gestão, tornandoa mais transparente e evitando ilegalidades.

Os dirigentes colaboradores envolvidos em investigação criminal, cujas provas não lhes forem favoráveis, tenderão a confessar a autoria delituosa, mesmo quand o não forem de fato os autores, visando lograr os benefícios do acordo e a ausência do risco de se depararem com uma sentença condenatória que resulte em privação de liberdade e registro de antecedentes criminais. O investigado ou acusado por um delito de "colarinho branco" que vislumbrar possibilidade de condenação, mesmo quando não for o autor do delito, poderá vir a optar pelo cenário que apresente menos riscos para si próprio.

Tal atitude produzirá reflexos na empresa, que sofrerá civil, tributária e administrativamente sanções legais necessitando, em inversão probatória, produzir provas hábeis para afastar sua responsabilidade penal, em um contexto em que já há a confissão do investigado inicial.

Nesse viés, considerando a decorrência de "crimes de colarinho branco" no contexto empresarial e a aplicabilidade do Acordo de Não Persecução Penal diante de tais crimes, possivelmente haverá um aumento na quantidade de processos administrativos e de situações passíveis de configurar a responsabilidade objetiva das empresas.

Tal novo panorama exigirá por parte das empresa, uma reestruturação administrativa e estratégica no aspecto defensivo, aderind ò̀s práticas de compliance e, ainda, por consequência, aumentará a quantidade de acordos de leniência e de Acordos de Não Persecução Civil.

Destarte, em contrapartida, as empresas, diante dos maiores riscos de serem responsabilizadas por possíveis condenações de seus colaboradores, no geral serão induzidas a não compactuarem com posturas antiéticas, corruptas e criminosas.

Claramente se vislumbra que, para a empresa, será mais vantajoso prezar pela adoção de maiores posturas de integridade e ética coorporativa - o quê inibirá a quantidade de cometimento de "crimes de colarinho branco" no ambiente empresarial. As corporações, portanto, deverão se reorganizar administrativamente, voltando sua gestão e cuid ad os de forma mais intensa à sua cultura corporativa e postura moral, legal e ética de seus dirigentes e funcionários, devendo sustentar, sempre, um desestímulo a condutas fraudulentas e criminosas, seja por parte das lideranças ou dos colaboradores. 
A consequência clara de tais práticas será uma sociedade mais justa, com práticas comerciais e empresariais transparentes, colaborando para a paz social e diminuindo a incidência enorme de crimes no Brasil, inclusive a própria corrupção endêmica na administração pública.

\section{REFERÊNCIAS BIBLIOGRÁFICAS}

BRASIL. Ministério Público Federal. MPF - Acordos de Não Persecução Penal. s.d. Disponível em: <http://www.mpf.mp.br/pgr/documentos/mpfacordosnaopersecu caopenal.pdf/view>. Acesso em: 23 de novembro de 2020.

. Lei no 9.099, 26 de setembro de 1995. Dispõe sobre os Juizados Especiais Cíveis e Criminais e dá outras providências. Diário Oficial da União. Disponível em: <http://www.planalto.gov.br/ccivil_03/Leis/L9099.htm>. Acesso em 23 de novembro de 2020.

Lei 12.846, de $1^{\circ}$ de agosto de 2013. Dispõe sobre a responsabilização administrativa e civil de pessoas jurídicas pela prática de atos contra a administração pública, nacional ou estrangeira, e dá outras providências. Diário Oficial da União. Disponível em: <http://www.planalto.gov.br/CCIVIL_03/_Ato2011-2014/2013/Lei/L12846.htm>. Acesso em 23 de novembro de 2020

. Lei $\mathbf{n}^{\circ} \mathbf{1 2 . 8 5 0}$, de 2 de agosto de 2013. Define organização criminosa e dispõe sobre a investigação criminal, os meios de obtenção da prova, infrações penais correlatas e o procedimento criminal; altera o Decreto-Lei ${ }^{\circ}$ 2.848, de 7 de dezembro de 1940 (Código Penal); revoga a Lei ${ }^{\circ}$ 9.034, de 3 de maio de 1995; e dá outras providências. Disponível em: <http://www.planalto.gov.br/ccivil_03/_Ato2011-2014/2013/Lei/L12850.htm > . Acesso em 23 de novembro de 2020.

Lei $n^{0}$ 13.964, de 24 de dezembro de 2019. Aperfeiçoa a legislação penal e processual penal. Diário Oficial da União. Disponível em: <http://www.planalto.gov.br/ccivil_03/_ato2019-2022/2019/lei/L13964.htm>. Acesso em 23 de novembro de 2020.

Lei no 13.964, de 24 de dezembro de 2019. Aperfeiçoa a legislação penal e processual penal. Diário Oficial da União. Disponível em: <http://www.planalto.gov.br/ccivil_03/_ato2019-2022/2019/lei/L13964.htm>. Acesso em 23 de novembro de 2020.

CABRERA, R.P. Tratado de Derecho Penal. vol. IIII. Lima: Ediciones Jurídicas, 1994 CAPANEMA, R.O. Lei Anticorrupção Empresarial - Aspectos críticos à Lei nº 12.846/2013. 1ed. Belo Horizonte: Fórum, 2014.

CASTRO, L.A.C. Criminologia da reação social. Trad. Ester kosovski. Rio de Janeiro: Forense, 1983.

COSTA, José Faria, Direito Penal e a Globalização, $1^{\text {a }}$ Ed., Coimbra: Coimbra Editora, 2010. Rev. CEJUR/TJSC |Florianópolis (SC) | v.9.n.1|e360| p.01-15 | Janeiro-Dezembro | 2021. 
CRUZ, Rogério Schietti. Prisão cautelar, dramas, princípios e alternativas. 5 ed. Salvador: Juspovium, 2020

EUA. Federal Bureau of Investigation (FBI). White Collar crime. Disponível em <https://www.fbi.gov/investigate/white-collar-crime>. Acesso em: 02 de dezembro de 2020. FRAGOSO, H.C. Lições de direito penal: parte geral. Rio de Janeiro: Forense, 2004.

FRIEDRICHS, David O, Trusted Criminals: White Collar Crime in Contemporary Society, 4th Edition, 2010.

Geis, G., Meier, R. \& Salinger, L. White-collar Crime: Classic \& Contemporary Views. NY: Free Press, 1995

Green, Stuart P. Lying, Cheating, and Stealing: A Moral Theory of White Collar Crime. Oxford: Oxford University Press, 2006

LAVILLE, C.; DOINNE, J. A construção do saber: manual de metodologia da pesquisa em ciências humanas. Porto Alegre: Artmed, 1999.

LIMA, R.B. de. Manual de processo penal: volume único. 8 ed.rev., ampl. e atual. Salvador: Editora Juspodivm, 2020.

LOPES JUNIOR, A. Direito processual penal. 17ed. São Paulo: Saraiva Jur., 2020.

MACHADO, B.A. Controle penal dos crimes de colarinho branco no Brasil: de Sutherland a Baratta - reflexões sobre uma política criminal possível. Rev. da Fund. Esc. Sup. do MP do DF e Ter. Brasília, v. 10, n. 18, p. 42-72, jul./dez. 2001.

MARCONI, M.A.; LAKATOS, E.M. Fundamentos de metodologia científica. 8ed. São Paulo: Atlas, 2017.

MASSON, C.; MARÇAL, V. Crime organizado. 5ed. Rio de Janeiro: Forense, 2020.

OLIVEIRA, Almerinda Alves de. O teste de integridade dos agentes públicos como ferramenta de combate à corrupção: validade e efetividade. Revista da Controlad oria Geral da União. Volume 9, n. 15, p. 619-639, 2017.

OLIVEIRA, E.P. de. Curso de processo penal. 12ed. Rio de Janeiro: Lumen Juris, 2009.

PRADO, L.R. Curso de direito penal brasileiro. 17ed. Rio de Janeiro: Forense, 2019.

SANTOS, J.C. dos. Direito penal: parte geral. 8 ed. Florianópolis: Tirant lo Blanch, 2018.

SILVA SANCHEZ, Jesús-María, A expansão do direito penal: aspectos da política criminal nas sociedades pós-industriais - tradução Luiz Otávio de Oliveira Rocha - $3^{\mathrm{a}}$ ed. rev. atual., São Paulo: Editora Revista dos Tribunais, 2013 
SOUZA, R.Ó.; CUNHA et al. Acordo de Não Persecução Penal. São Paulo: JusPODVM, 2020.

SUTHERLAND, E.H. Crime de colarinho branco: versão sem cortes. Coleção Pensamento Criminológico, n. 22. Trad. Clécio Lemos. Revan: Rio de Janeiro, 2015.

fev., 1940.

White collar criminality. American Sociological Review. v. 5, n. 1, p. 01-12,

TOLEDO, F.A. Princípios básicos de direito penal. 5ed. São Paulo: Saraiva, 1994.

TRANSPARENCY INTERNATIONAL. Daphnee Iglesias. Open data and the fight against corruption in Brazil. Berlin, 2017.

TRANSPARENCY INTERNATIONAL, Jeremy Pope. Confronting corruption: the elements of a national integrity system. Berlin, 2000.

SANCHES, F.J. La integridade de los gobernantes como problema de acción colectiva. Rev. Inter. Transp. e Int. <Disponível em https://revistainternacionaltransparencia.org/wpcontent/uploads/2016/12/Fernando-Jim\%C3\%A9nez.pdf >, Acesso em 02 dez 2020, Múrcia (Espanha), 2016

UNITED NATIONS Handbook on. Practical anti-corruption measures for prosecutors and investigators. Vienna, September. Disponível <http://www.unodc.org/documents/treaties/corruption/Handbook.pdf >. Acesso em: 2 dez. 2020,2004

WELZEL, H. Derecho Penal Alemán. Juan Brestos Pamírez e Sérgio Yánez Pérez (trad). Santiago: Editora Jurídica de Chile, 1970

ZAFFARONI, E.R. Manual de Derecho Penal. Buenos Aires: Ediar, 1991. 